\title{
O Brasil e as \\ Operações de Manutenção da Paz da ONU: Os Casos do Timor Leste e Haiti*
}

\section{Djuan Bracey**}

\section{Introdução}

O papel do Brasil nas operações de manutenção da paz da Organização das Nações Unidas (ONU) merece muita atenção dada a sua ascensão como a potência regional mais forte na América Latina. O país participou de cinco operações de paz no Timor Leste desde 1999 e contribui preponderantemente na Missão das Nações Unidas para estabilização no Haiti (do francês, Mission des Nations Unies pour la Stabilisation en Haiti [Minustah]) desde 2004. No início de 2011, a presidente Dilma Rousseff reafirmou o compromisso contínuo da nação brasileira com as intervenções internacionais, observando, após o catastrófico terremoto de janeiro de 2010 em Porto Príncipe, que "[a] Minustah e [o] Brasil continuarão" (EM NOTA..., 2011).

Este trabalho examina as motivações do Brasil para contribuir para missões de manutenção da paz e os fatores que moldam o escopo e a natureza da sua participação. Prestígio é o primeiro incentivo (FISHEL; SAENZ, 2007, p. 199). Brasília acredita que a participação nas missões aumentará a reputação internacional e aumentará a projeção

\footnotetext{
* Artigo recebido em 9 de agosto de 2010 e aprovado para publicação em 13 de dezembro de 2010. Traduzido por Fernando Neves da Costa Maia. E-mail: fncmaia@terra.com.br.

** Mestre em Relações Internacionais pela Universidade de Georgetown, Washington, D.C., e bacharel em História pela Universidade do Sul da Flórida, Tampa, EUA. E-mail: djuanbracey@gmail.com.
} 
de poder econômico e político do país. O prestígio está associado também ao objetivo de obter um assento permanente no Conselho de Segurança da ONU, posição que garantiria ao Brasil maior peso regional na América Latina e uma forte presença nos assuntos militares e econômicos internacionais.

As contribuições do Brasil para as missões de manutenção da paz também estão ligadas a objetivos pragmáticos de sua política externa. Brasília adere fortemente ao multilateralismo e percebe sua participação em organizações internacionais como um mecanismo de correção dos desequilíbrios no sistema internacional, que favorecem as nações mais ricas (MONTERO, 2005, p. 129).

O Brasil contribui com mais frequência para missões em regiões que considera estrategicamente importantes, incluindo a América Latina, outras nações de língua portuguesa e do mundo em desenvolvimento. Também participa de intervenções das Nações Unidas para obter treinamento para suas Forças Armadas e reforçar os laços militares com outras nações sul-americanas que também contribuem para as missões.

A primeira seção deste trabalho aborda a evolução das missões de manutenção da paz da ONU e da política externa do Brasil. As duas seções seguintes examinam o papel do Brasil no Timor Leste e no Haiti. A seção final aborda o debate em torno das missões de manutenção da paz nos círculos de formulação de política no Brasil.

\section{As Operações de Manutenção da Paz da ONU e a Política Externa Brasileira: Um Panorama}

A ONU declara no site do Department of Peacekeeping Operations que a manutenção da paz é "um instrumento único e dinâmico desenvolvido pela Organização como uma maneira de ajudar os países afetados por conflitos a criarem as condições para uma paz duradoura". 1 Não obstante, a Carta da ONU falha em mencionar o termo explicitamente, além de carecer de definições claras. Dag Hammarskjöld, o segundo secretário-geral da Organização, referia-se à manutenção da 


\section{O Brasil e as Operações de Manutenção da Paz da \\ ONU: Os Casos do Timor Leste e Haiti}

paz como estando amparada pelo "capítulo seis e meio" da Carta, situando-se entre o capítulo VI, que requer que os Estados membros resolvam suas disputas por meio da mediação, negociação e arbitragem, e o capítulo VII, que outorga ao Conselho de Segurança a competência para manter a paz e a segurança internacionais por meio de uma intervenção forçada (isto é, missões de imposição da paz).

O Brasil tradicionalmente tem fortes reservas em participar de intervenções baseadas no capítulo VII, preferindo, em vez disso, contribuir para aquelas baseadas no capítulo VI que exigem consentimento das partes envolvidas em um conflito (DINIZ, 2007, p. 95). Brasília também insiste que as missões de paz devem ser criadas multilateralmente e devem lidar com o que ela considera como as causas primárias da guerra: pobreza, subdesenvolvimento e desigualdade econômica e social (DINIZ, 2007, p. 95). O país também tem se preocupado com a possibilidade de os Estados Unidos ou outras grandes potências concorrentes empregarem indevidamente as operações de imposição da paz para impor políticas unilaterais.

Durante a Guerra Fria, o Conselho de Segurança enfrentou uma paralisia sistêmica causada pelo frequente uso do poder de veto pelos EUA e pela União Soviética, o que limitava sobremaneira a agenda de manutenção da paz do Conselho. Entre 1945 e 1988, a ONU aprovou apenas treze missões com consentimento dos governos receptores. $\mathrm{O}$ fim da Guerra Fria, desde então, levou a uma maior cooperação entre os membros do Conselho e a um aumento do número de ações de imposição com base no capítulo VII.

Este fato explica um aparente paradoxo: por volta do ano 2002, o Brasil havia participado de 26 das 54 missões das operações de paz da ONU, mas participou de apenas 11 das 37 desde 1989. Em outras palavras, o Brasil participou de quase metade das missões de operação de paz da ONU desde o seu primeiro envolvimento em 1956, quando disponibilizou tropas para intervir na Crise de Suez. Contudo, ele participou de menos de um terço de todas as missões de manutenção da paz no período entre 1989 e 2002, período em que sua demanda por um assento permanente foi mais amplamente vocalizada. Essa é uma queda significativa desde o período entre 1956 e 1989, quando os bra- 
sileiros participaram de 15 de 17, ou seja, quase 90\% das missões de operação de paz da ONU (SOUZA NETO, 2009, p. 6).

A participação brasileira no Timor Leste e Haiti reflete a natureza crescentemente pragmática de sua política externa na busca por maior prestígio internacional. No caso do Timor Leste, o Brasil envolveu-se em duas operações de paz com mandatos baseados no capítulo VII (SOUZA NETO, 2009). A primeira foi a Força Internacional para o Timor Leste (em inglês, International Force for East Timor [INTERFET]) em 1999, uma força-tarefa estabelecida pela Resolução 1264 (ORGANIZAÇÃO DAS NAÇÕES UNIDAS, 1999b) em resposta ao declínio da situação humanitária e de segurança durante a transição timorense para a independência da Indonésia. A segunda operação foi a Missão de Apoio das Nações Unidas para o Timor Leste (em inglês, United Nations Mission of Support to East Timor [UNMISET]) em 2002, estabelecida pela Resolução 1410 (ORGANIZAÇÃO DAS NAÇÕES UNIDAS, 2002) para prestar assistência ao Timor Leste até que todas as responsabilidades operacionais fossem integralmente transferidas para o governo timorense dois anos depois. O Brasil aproximou-se dos mandatos de imposição, justificando seu papel nos laços culturais e linguísticos comuns entre os dois Estados e no fato de que o consentimento foi dado pelas partes hostis (SOUZA NETO, 2009, p. 6).

A decisão brasileira de participar da Minustah revela justificativas similares e sutilezas interpretativas. No dia 29 de fevereiro de 2004, o Brasil votou favoravelmente à Resolução 1529 (ORGANIZAÇÃO DAS NAÇÕES UNIDAS, 2004a), que estabeleceu a Força Multinacional Interina para oferecer ajuda e assistência à polícia e à guarda costeira haitianas, mas não participou da força (GAUTHIER; SOUSA, 2006, p. 2). Brasília afirmou que a resolução era uma missão de imposição da paz porque agiu sob o capítulo VII e que o Brasil aceitaria participar apenas em um "momento subsequente" em uma missão de manutenção da paz baseada no capítulo VI. Tal momento veio com a aprovação da Resolução 1542 (ORGANIZAÇÃO DAS NAÇÕES UNIDAS, 2004b), que autorizou a Minustah. Existe uma inconsistência nisso porque essa resolução também atua amparada pelo capítulo 
VII, embora Brasília negue tal argumento, pois a referência ao capítulo VII foi feita no preâmbulo da Resolução 1529 , e também no sétimo parágrafo da Resolução 1542. Desse modo, o Brasil afirma que apenas esse parágrafo está amparado pelo capítulo VII e não toda a resolução (GAUTHIER; SOUSA, 2006 p. 2).

A recente disposição do Brasil de participar dessas missões deve ser vista como resultado de sua política externa mais agressiva e pragmática no período pós-Guerra Fria. Durante o período da ditadura militar, que durou de 1964 a 1985, os líderes brasileiros rejeitaram as organizações internacionais, vendo-as como figurantes na rivalidade das superpotências e, portanto, como apoiadoras do desequilíbrio do poder global (DINIZ, 2007, p. 95). Tal postura mudou durante o retorno da democracia como resultado da maior consciência da globalização após o fim da Guerra Fria. Os líderes civis adotaram desde então uma política de "autonomia por meio da integração" (DINIZ, 2007, p. 95), o que exige uma participação ativa em organizações multilaterais a fim de melhorar a competitividade econômica do Brasil, ter acesso a mercados globais e melhorar suas capacidades de defesa. Um dos primeiros sinais dessa mudança de política foi o retorno do Brasil para o Conselho de Segurança como um membro não permanente em 1988 depois de uma ausência de vinte anos. Desde então, o Brasil serviu por mais quatro mandatos de dois anos em 1993-1994, 1998-1999, 2004-2005 e 2010-2011 (DINIZ, 2007, p. 95). Até o momento, o Brasil tem sido um membro não permanente por dezoito anos, tempo igualado apenas pelo Japão (GRATIUS, 2007, p. 1).

A participação nas missões também permite ao Brasil buscar dois outros objetivos fundamentais: solidariedade regional na América Latina e relações comerciais mais intensas com o sul global. De acordo com a Constituição da República de 1988, o Brasil busca a "integração econômica, política, social e cultural dos povos da América Latina, visando à formação de uma comunidade latino-americana de nações". Os líderes civis pós-ditadura priorizaram o livre comércio para compensar a concorrência dos Estados Unidos, cujo mercado lucrativo ameaçou reduzir a capacidade de negociação comercial do Brasil com países vizinhos. Essa competição e as falhas do modelo econômico 
protecionista da ditadura levaram à criação do Mercado Comum do Sul (Mercosul) com Argentina, Paraguai e Uruguai em 1991, buscando novos mercados e oportunidades de comércio (DINIZ, 2007, p. 97). A política externa civil brasileira também priorizou laços fortes com o mundo em desenvolvimento a fim de estender seus interesses econômicos para além da sua esfera de influência tradicional.

Essas áreas de importância estratégica e econômica são fortes fatores na localização e escopo da presença do Brasil nas operações de manutenção da paz. Embora o Brasil tenha participado de operações em todos os continentes, suas intervenções mais frequentes e amplas refletem seus interesses geopolíticos. Entre 1989 e 1999, o Brasil enviou tropas para El Salvador, Moçambique, Ruanda, Uganda, Macedônia, Libéria, Guatemala, Angola, Chipre e Timor Leste (FONTOURA, 2005, p. 224). A maior parte dessas contribuições foi, de longe, feita na Terceira Missão de Verificação das Nações Unidas em Angola (em inglês, United Nations Angola Verification Mission III [UNAVEM III]) para a qual o Brasil enviou um total de 4.174 soldados e 48 policiais entre 1995 e 1996 (FONTOURA, 2005, p. 219). A segunda maior contribuição foi para a Operação das Nações Unidas em Moçambique (em inglês, United Nations Operation in Mozambique [ONUMOZ]), para a qual foram enviados 218 soldados e 16 policiais entre 1992 e 1994 (FONTOURA, 2005, p. 219). Comparativamente, o Brasil enviou menos de cem soldados para outras missões das quais tenha participado. Seu grande envolvimento em Angola e Moçambique foi baseado primeiramente nos incentivos econômicos, em particular no desenvolvimento da indústria de petróleo de Angola (HUNTER, 1996, p. 24), e na sua busca por relações mais fortes com outros países de língua portuguesa (FONTOURA, 2005, p. 229).

\section{O Brasil no Timor Leste}

A natureza pragmática da política externa brasileira é claramente percebida em suas contribuições no Timor Leste. No final dos anos 1990, a administração do presidente Fernando Henrique Cardoso buscou laços econômicos e políticos mais fortes fora da Europa e dos Estados Unidos. O sudeste asiático tornou-se uma região atrativa dada a emer- 


\section{O Brasil e as Operações de Manutenção da Paz da \\ ONU: Os Casos do Timor Leste e Haiti}

gência de novas economias industrializadas na região, incluindo os "Quatro Tigres Asiáticos" (PEPE; MATHIAS, 2006 p. 52). O Timor Leste, portanto, criou uma oportunidade única para o Brasil: sua condição de ex-colônia portuguesa em uma luta de grande visibilidade para a independência permitiu ao país demonstrar ativamente a sua política externa independente, seu compromisso com a autodeterminação e sua expansão dos laços econômicos com o sul global (PEPE; MATHIAS, 2006, p. 52).

O Timor Leste chamou atenção da comunidade internacional pela primeira vez nos anos 1990 quando sua luta para por fim a 25 anos de ocupação indonésia se tornou violenta (PEPE; MATHIAS, 2006, p. 52). Com o consentimento dos governos indonésio e português, o Conselho de Segurança autorizou a Resolução 1246 (ORGANIZAÇÃO DAS NAÇÕES UNIDAS, 1999a), que estabeleceu a Missão das Nações Unidas no Timor Leste (em inglês, United Nations Mission in East Timor [UNAMET]) em 1999. O objetivo dessa missão era realizar um referendo para determinar se a população timorense apoiava a criação de uma região autônoma especial ou a independência da Indonésia. Após o referendo revelar um claro apoio à soberania, a ONU enviou novecentos soldados para servir na INTERFET sob a liderança australiana após os milicianos pró-Jacarta entrarem em confronto com os timorenses.

A Administração Transitória das Nações Unidas em Timor Leste (em inglês, United Nations Transitional Administration in East Timor [UNTAET]), notavelmente liderada pelo diplomata Sérgio Vieira de Mello como o representante especial do secretário-geral da ONU, seguiu a UNAMET e a INTERFET em 1999 e durou até a independência do Timor Leste em 2002. O objetivo da UNTAET era criar um governo interino para prestar assistência humanitária, ajudar no desenvolvimento, apoiar medidas de capacitação da população e oferecer segurança e manter a lei e a ordem. A UNIMITSET seguiu a UNTAET quando a independência foi alcançada com o objetivo de ajudar o novo governo, promover interinamente a imposição da lei e manter a segurança timorense. A Missão Integrada das Nações Unidas no Timor Leste (em inglês, United Nations Integrated Mission in East Timor [UNMIT]) é uma 
missão em curso estabelecida em 2006 pela Resolução 1704 (ORGANIZAÇÃO DAS NAÇÕES UNIDAS, 2006) com o objetivo de consolidar a estabilidade, promover uma governança democrática e facilitar o diálogo político com a comunidade timorense.

Dessas missões, o Brasil participou da UNAMET, INTERFET, UNTAET, UNMISET, e da UNMIT. O papel mais crítico de Brasília nelas foi o de mediador, uma posição que tem mantido na medida em que busca preservar cautelosamente sua neutralidade a fim de manter relações amistosas com os timorenses e com o governo indonésio (PEPE; MATHIAS, 2006, p. 55). A presença de tropas brasileiras foi, comparativamente, limitada; o governo de Fernando Henrique enviou apenas 57 soldados para a INTERFET e 91 para UNTAET (PEPE; MATHIAS, 2006, p. 62). O Brasil optou por seu papel de árbitro em função dos seus interesses econômicos na Indonésia, cuja economia oferece oportunidades de investimento promissoras (PEPE; MATHIAS, 2006, p. 51). Juntamente com os seus compromissos de manutenção da paz, o Brasil continua a desempenhar um papel forte no desenvolvimento e educação no Timor Leste, a fim de assegurar a sua presença na região (PEPE; MATHIAS, 2006, p. 62).

Desse modo, o papel do Brasil no Timor Leste esteve amplamente associado aos seus objetivos pragmáticos de cunho econômico e político. Com o fim da Guerra Fria, as atividades da ONU tornaram-se mais multidimensionais e priorizaram o ambiente pós-conflito para desenvolver as condições necessárias para evitar futuros surtos de violência. Essas novas características das ações da ONU permitiram ao Brasil tornar público os aspectos humanitários de sua política externa e sua disposição de comprometer-se em longo prazo com a construção do Estado do Timor Leste. A ênfase do governo Fernando Henrique nos direitos humanos e democratização também permitiu ao Brasil mostrar para o mundo sua transição do regime autoritário.

A aspiração brasileira por um assento permanente no Conselho de Segurança foi também um fator de engajamento no Timor Leste. O governo anunciou formalmente esse objetivo em 1994 (SOARES DE LIMA; HIRST, 2006, p. 29). O Timor Leste também permitiu que o Brasil legitimasse o seu status desejado, especialmente após o seu ar- 
gumento de reforma do Conselho de Segurança ter sido enfraquecido devido a sua oposição anterior às missões baseadas no capítulo VII.

\section{O Brasil no Haiti}

A decisão do Brasil de liderar a Minustah em fevereiro de 2004 marca mais um momento crítico na sua política externa. Desde a chegada de Luiz Inácio Lula da Silva ao poder em 2003, os elementos tradicionais da diplomacia brasileira têm sido afirmados com renovado vigor (DINIZ, 2007, p. 98). Como no caso do governo Fernando Henrique, a administração atual enfatiza a cooperação Sul-Sul, um engajamento ativo em parcerias globais e regionais e a preferência pelo multilateralismo. Lula ainda vai além destes pilares tradicionais da diplomacia brasileira, promovendo ativamente a sua aspiração por uma condição de "primeiro entre iguais" na América do Sul. A Minustah permitiu ao Brasil assumir esse papel de liderança entre as nações sul-americanas ao contribuir para a missão.

O Conselho de Segurança da ONU autorizou a Minustah em resposta ao colapso institucional no Haiti que se seguiu à renúncia de Jean-Bertrand Aristide em 29 de fevereiro de 2004. Essa renúncia veio a partir de pressões dos governos francês e estadunidense após as tensões entre opositores do líder haitiano e seus partidários resultarem em conflitos civis e em falência do estado. Este conflito se originou dos resultados controversos das eleições de 2000 que levaram Aristide ao poder pela segunda vez em um clima de intensa disputa. A Resolução 1529 afirma que o objetivo da missão é monitorar e reestruturar a polícia nacional haitiana; ajudar no desarmamento, desmobilização e reintegração das milícias armadas; restaurar e manter o Estado de direito; e proteger o pessoal da ONU e os civis locais. Um total de 12.279 soldados contribui para a missão. A ONU nota, em um relatório de abril de 2011, que o comprometimento das tropas brasileiras chega a 2.175 soldados. $^{2}$

A aspiração brasileira para obter um assento permanente no Conselho de Segurança talvez seja o fator mais visível responsável pelo papel do país na missão. Embora os funcionários diplomáticos tenham sido relutantes em associar publicamente a liderança do Brasil na Minustah 
com este objetivo, alguns membros do Congresso brasileiro, os líderes militares e ministros que ocuparam o Ministério da Defesa associam as duas questões. Luiz Carlos da Silva, líder do governo no Congresso, por exemplo, afirmou em 2004 que "é uma oportunidade singular para o Brasil continuar pleiteando um assento permanente nas Nações Unidas, o que permitiu nosso país não só enviar tropas para o Haiti, mas também comandá-las" (GAUTHIER; SOUSA, 2006, p. 1). Lula também fez do assento permanente um objetivo desde o início de sua Presidência, observando em seu discurso de posse que ele iria trabalhar para "um Conselho de Segurança reformado, representando a realidade dos dias de hoje, com os países desenvolvidos e em desenvolvimento de todas as regiões do mundo entre os seus membros permanentes" (DINIZ, 2007, p. 100).

A liderança do Brasil na Minustah pode ter legitimado seu desejo de servir como o representante latino-americano permanente no Conselho de Segurança. A aceitação argentina do papel de liderança do Brasil é significativa porque os dois países são, historicamente, rivais e competidores continentais por um assento no Conselho. Ao aceitar a liderança brasileira, a Argentina pode estar indicando uma mudança política em favor da posição brasileira.

A Minustah também legitima a aspiração brasileira por um status de hegemonia regional. A missão é importante como a primeira operação de paz composta por uma maioria de países latino-americanos, com Argentina e Chile figurando entre os maiores contribuintes (FISHEL; SAENZ, 2007, p. 198). De acordo com a declaração do ministro da Defesa argentino, essas nações estavam motivadas "a mostrar que a América Latina amadureceu” (FISHEL; SAENZ, 2007, p. 200). Por liderar a missão, o Brasil é o representante mais visível da crescente influência internacional da região.

Ademais, a participação no Haiti tem permitido uma coordenação política e econômica mais estreita entre as nações sul-americanas. O Brasil percebe seu papel de liderança como crucial para a reabertura de negociações de livre comércio na América do Sul, incluindo os impasses atuais nas discussões no âmbito do Mercosul (DINIZ, 2007, p. 100). 
A decisão de liderar a Minustah está também ligada à crescente agenda militar brasileira e à melhoria das relações civis-militares. A missão serve como uma oportunidade para os militares aprofundarem seus laços com o Ministério das Relações Exteriores a fim de revelar o papel mais ativo do Brasil na segurança internacional e nos futuros compromissos de estabilização e esforços contra novas ameaças e conflitos (HIRST, 2009, p. 10). Ela também permite às Forças Armadas participarem diretamente na "diplomacia presidencial" do Brasil, em que o chefe do Poder Executivo serve como o principal árbitro da imagem do país no exterior. Estas considerações são percebidas na Estratégia Nacional de Defesa do Brasil de 2008, que afirma: "o Brasil deve expandir sua participação em operações de paz, sob a égide da ONU ou de uma organização regional multilateral, de acordo com os interesses nacionais expressos nos compromissos internacionais" (BRASIL, 2008).

\section{Debate sobre as Missões de Manutenção da Paz}

No dia 12 de janeiro de 2010, um catastrófico terremoto devastou a capital haitiana de Porto Príncipe, matando cerca de 230 mil pessoas e deixando alguns milhões desabrigados. Dezoito soldados brasileiros que integravam a Minustah também morreram. ${ }^{3}$ Um debate sobre a necessidade da contínua participação do Brasil na missão instantaneamente veio à tona. Comentários controversos feitos por George Samuel Antoine, ${ }^{4}$ cônsul do Brasil em Porto Príncipe, logo após o desastre pareciam ir ao encontro do ponto de vista de muitos observadores brasileiros: o Haiti estava condenado ao fracasso, e a contínua intervenção lá não produziu nenhum benefício.

Oposição à participação brasileira baseada nesses argumentos não é algo novo. Os primeiros observadores descreveram a Minustah como uma "missão impossível" em razão das condições violentas no Estado. Observadores haitianos também expressaram preocupações semelhantes. Moradores de Cité Soleil, uma favela de Porto Príncipe, disseram que forças de paz brasileiras têm tradicionalmente sido mais relutantes em intervir em conflitos, e acusou-as de "assistir [de seus] carros blin- 
dados da ONU e de não interferir quando o tiroteio começa" (GAUTHIER; SOUSA, 2006, p. 4).

Alguns oficiais militares brasileiros têm preocupações semelhantes. $\mathrm{O}$ general Augusto Heleno Ribeiro Pereira, um ex-comandante da Minustah, afirmou que os militares brasileiros não foram capazes de cumprir o seu papel no Haiti, descrevendo a missão como "ingenuamente utópica e cruel”. Álvaro Augusto Dias Monteiro, comandante-geral do Corpo de Fuzileiros Navais, em uma conferência na Pontifícia Universidade Católica do Rio de Janeiro, publicamente duvidou de que os militares estavam suficientemente treinados para realizar a missão (SARMIENTO, 2010, p. 82).

Outros opositores da missão também argumentaram que a participação do Brasil foi desfavorável em razão de uma percepção de violação da soberania haitiana. Pelo fato de que os Estados Unidos teriam apoiado a remoção forçada de Jean-Bertrand Aristide do poder em 2004, os opositores alegaram que a presença contínua de tropas estrangeiras constitui uma força de ocupação. De acordo com essa visão, o deputado Ivan Valente afirmou que "a missão legitima a 'política imperialista e intervencionista' de potências estrangeiras, especialmente os Estados Unidos" (GAUTHIER; SOUSA, 2006, p. 3).

Os oponentes também citam custos econômicos existentes. Os críticos alegam que a receita gasta em intervenções das Nações Unidas deveria ter sido utilizada em projetos sociais locais. Os custos associados com a Minustah inevitavelmente aumentaram com o terremoto de janeiro de 2010. O Brasil autorizou 375 milhões de reais para financiamentos após o desastre. Celso Amorim, então ministro das Relações Exteriores, também anunciou um adicional de 172 milhões de reais a ser dado ao esforço de reconstrução do Haiti (RAMALHO; GOES, 2010, p. 64).

No entanto, os defensores da participação rebatem esses argumentos apontando as vantagens de longo prazo das missões de paz. De acordo com Fernando Cavalcante (2010, p. 7), da Universidade de Coimbra, missões de paz são benéficas como "investimentos de baixo custo com alto retorno" para o Exército brasileiro. Cavalcante considera as intervenções das Nações Unidas investimentos de baixo custo porque a Or- 
ganização recupera a maior parte dos custos das missões de paz enquanto fornece treinamento para as Forças Armadas. O custo das missões é considerado baixo pelo fato de os riscos associados às missões de manutenção da paz serem inferiores aos de uma guerra em grande escala. As intervenções da ONU também permitem que o Exército compare suas operações estratégicas com as de outras Forças Armadas, ganhe experiência em logística e inteligência, melhore a tecnologia e utilize a formação adquirida de outras nações. Como as nações da América do Sul são as principais contribuintes para a Minustah, a missão em curso no Haiti permite uma maior cooperação militar regional.

$\mathrm{O}$ argumento sobre os custos econômicos das missões de manutenção da paz pode ser igualmente rebatido. Apesar de os custos associados às missões de manutenção da paz da ONU terem aumentado $50 \%$ até seu nível atual de mais de 2,5 bilhões de dólares no período entre 2005 e 2010, a maior parte dos custos caiu sobre as nações desenvolvidas (RAMALHO; GOES, 2010, p. 63). Em 2010, os Estados Unidos forneceram $27 \%$ dos fundos necessários para o orçamento das missões de manutenção da paz da ONU. Os outros maiores contribuintes - Japão, Reino Unido, Alemanha, França, Itália, China, Canadá, Espanha e Coreia do Sul - forneceram um adicional de 53\%. O Brasil, por outro lado, contribuiu com 0,3\% no período entre 2010 e 2012, acima dos 0,17\% em 2009 (RAMALHO; GOES, 2010, p. 63).

\section{Conclusão}

As operações de manutenção da paz devem ser consideradas um mecanismo favorável para as aspirações globais do Brasil. Apesar dos desafios de segurança, as missões da ONU permitem o treinamento das Forças Armadas e integração militar na América do Sul a um custo relativamente baixo. As missões também permitem um maior prestígio internacional. A presença do Brasil em nações amigas de língua portuguesa e no mundo em desenvolvimento legitima seu status de potência econômica e militar no sul global. Além disso, o Brasil, com suas contribuições, fortalece sua busca por um assento permanente no Conselho de Segurança da ONU. 
Contribuições futuras do Brasil em missões de paz da ONU continuarão a refletir o viés pragmático de sua política externa. O país buscará maior prestígio para mostrar sua emergência como uma potência econômica e política por meio da ação na ONU.

\section{Notas}

1 Disponível em: <http://www.un.org/en/peacekeeping/>. Acesso em: 7 fev. 2012.

2 Disponível em: <http://www.un.org/en/peacekeeping/missions/minustah/facts. shtml>. Acesso em: jan. 2012.

3 De acordo com o pronunciamento de Dilma Rousseff.

4 Antoine observou que as nações com maioria populacional afrodescendente estavam perpetuamente condenadas (OUTRAGE..., 2010).

\section{Referências Bỉbliográficas}

BRASIL. Ministério da Defesa. Estratégia Nacional de Defesa. Brasília: Ministério da Defesa, 2008. Disponível em: <http://www.esg.br/uploads/2011/02/estrategia _defesa_nacional_portugues.pdf $>$. Acesso em: 20 mai. 2011.

CAVALCANTE, Fernando. Revisitando o debate nacional: cinco anos da missão no Haiti. Coimbra: Universidade de Coimbra, 2010.

DINIZ, Eugenio. Peacekeeping and the evolution of foreign policy. In: FISHEL, J.; SAENZ, A. (Ed.). Capacity-building for peacekeeping: the case of Haiti. Washington, D.C.: Center for Hemispheric Defense Studies, National Defense University Press, 2007.

EM NOTA, Dilma relembra um ano do terremoto do Haiti. O Globo, 12 jan. 2011. Disponível em: < http://oglobo.globo.com/mundo/em-nota-dilma-relembraum-ano-do-terremoto-do-haiti-2839179>. Acesso em: 12 jan. 12. 


\section{O Brasil e as Operações de Manutenção da Paz da ONU: Os Casos do Timor Leste e Haiti}

FISHEL, John; SAENZ, Andrés. Capacity-building for peacekeeping: the case of Haiti. Washington, D.C.: Center for Hemispheric Defense Studies, National Defense University Press, 2007.

FONTOURA, Paulo Roberto. O Brasil e as Operações de Paz. Brasília: Instituto Rio Branco, 2005.

GAUTHIER, Amelie; SOUSA, Sarah. Brazil in Haiti: debate over the peacekeeping mission. Fundación para las Relaciones Internacionales y Del Dialogo Exterior, 2006. Disponível em: <http://www.fride.org/eng/File/ViewFile.aspx?FileId $=1193>$. Acesso em: 20 mai. 2011 .

GRATIUS, Susanne. Brasil en las Americas: ¿Una potencia regional pacificadora? Working Paper, n. 35, Fundación para las Relaciones Internacionales y del Dialogo Exterior, 2007. Disponível em: <http://www.fride. org/eng/ Publications/Publication.aspx?Item=1282>. Acesso em: 20 mai. 2011.

HIRST, Monica. Strategic posture review: Brazil. World Politics Review, set. 2009.

HUNTER, Wendy. State and soldier in Latin America: redefining the military's role in Argentina, Brazil, and Chile. Peaceworks, n. 10, out. 1996.

MONTERO, Alfredo. Brazilian politics: reforming a democratic State in a changing world. Cambridge: Polity Press, 2005.

ORGANIZAÇÃO DAS NAÇÕES UNIDAS. Conselho de Segurança. Resolução 1246, 11 jun. 1999a. Disponível em: <http://www.un.org/documents/scres.htm>. Acesso em: 7 fev. 2012.

Resolução 1264, 15 set. 1999b. Disponível em: <http://www.un.org/ documents/scres.htm>. Acesso em: 7 fev. 2012.

Resolução 1410, 12 mai. 2002. Disponível em: <http://www.un.org/ documents/scres.htm>. Acesso em: 7 fev. 2012.

Resolução 1529, 29 fev. 2004a. Disponível em: <http:/www.un.org/ documents/scres.htm>. Acesso em: 7 fev. 2012.

Resolução 1542, 30 abr. 2004b. Disponível em: <http://www.un.org/ documents/scres.htm>. Acesso em: 7 fev. 2012.

Resolução 1704, 25 ago. 2006. Disponível em: <http://www.un.org/ documents/scres.htm>. Acesso em: 7 fev. 2012. 
OUTRAGE over Pat Robertson's rant. BBC News, 17 Jan. 2010. Disponível em: $<$ http://www.bbc.co.uk/caribbean/news/story/2010/01/100117_roberston.shtml $>$. Acesso em: 12 jan. 2012.

PEPE, Leandro; MATHIAS, Suzeley Kalil. O envolvimento do Brasil na questão timorense. Lusotopie, v. 13, n. 2, p. 49-58, 2006.

RAMALHO, Antonio; GOES, Fernanda. Aspectos do financiamento das Operações de Paz da ONU: implicações para a política externa brasileira. In: Boletim de Economia e Política Internacional. Brasília: Instituto de Pesquisa Econômica Aplicada, 2010.

SARMIENTO, Luis. O Brasil e a Minustah: as motivações e consequências de uma operação liderada pelo Brasil. Fortaleza: Universidade Federal do Ceará, 2010.

SOARES DE LIMA, Maria; HIRST, Mônica. Brazil as an intermediate State and regional power: action, choice and responsibilities. International Affairs, v. 82, n. 1, p. 21-40, 2006.

SOUZA NETO, Danilo Marcondes de. Participação sul-americana em operações de paz: um estudo de caso da participação dos países do Cone Sul na Minustah. Revista Eletrônica Boletim do Tempo, v. 4, n. 3, 2009.

\section{Resumo}

\section{O Brasil e as Operações de Manutenção da Paz da ONU: Os Casos do Timor Leste e Haiti}

O presente artigo examina as motivações que o Brasil tem para contribuir para as missões de manutenção da paz (peacekeeping) das Nações Unidas no Timor Leste e no Haiti. O Brasil procura prestígio e aspira ganhar influência pelos métodos pragmáticos da sua política exterior. $\mathrm{Na}$ opinião do autor, as contribuições são vantajosas para o país porque o custo é baixo e porque permitem treinamento militar, visibilidade global e uma extensão política e econômica da influência brasileira.

Palavras-chave: Manutenção da Paz - Haiti - Minustah -Timor Leste 


\section{Abstract}

\section{Brazil and UN Peacekeeping: The Cases of East-Timor and Haiti}

The following article examines Brazil's motivations for contributing to peacekeeping missions. The work focuses on its participation in East-Timor and its leadership of the UN Stabilization Mission in Haiti. Brazil seeks prestige and hopes to gain influence through the pragmatic mechanisms of its foreign policy. The author believes the contributions are advantageous for the country, given the low cost of the missions, along with the receipt of military training, global visibility and an extension of Brazil's political and economic influence.

Keywords: Peacekeeping - Haiti - Minustah - East Timor 